\title{
Synergy of the future: high voltage insulated power cables and railway-highway structures
}

ISSN 1751-8687

Received on 6th January 2017

Revised 7th March 2017

Accepted on 17th March 2017 E-First on 12th July 2017 doi: 10.1049/iet-gtd.2016.2082 www.ietdl.org

\author{
Roberto Benato ${ }^{\circledR}$, Sebastian Dambone Sessa ${ }^{1}$, Luca Guizzo², Massimo Rebolini² \\ ${ }^{1}$ Industrial Engineering Department, University of Padova, Via Gradenigo 6/A 35131 Padova, Italy \\ ${ }^{2}$ Terna, Via Galbani 70, 00156 Rome, Italy \\ 凶E-mail: roberto.benato@unipd.it
}

\begin{abstract}
The rationalisation of the territorial resources leads to consider carefully the possibilities of using motorway and railway infrastructures (existing or planned ones) for cable line installation within them. The full compatibility of such synergy 'transport - electrical power transmission' involves different branches of engineering. The study provides an overview of the research undertaken for a fully reliable use of this combination. The manuscript aims at highlighting a procedural approach that should be followed in order to analyse all the key elements involved in the safe operation of power transmission lines hosted in transport infrastructures. First, the geometrical compatibility between different types of power transmission technologies, (i.e. gas insulated lines and high-voltage direct/alternating current insulated cable lines), and transport infrastructures (i.e. motorway galleries, railway galleries and railway prospection tunnels) is considered. Subsequently, the behaviour and magnitude of the magnetic field generated by the different power transmission technologies inside the transport infrastructures are presented. Moreover, the study analyses the effects of a phase-to-screen short circuit that could occur inside the hosting facility. Finally, an analysis of the reliability of the synergy between power transmission systems and transport infrastructures is discussed.
\end{abstract}

\section{Introduction}

The integration of power transmission lines in existing transport infrastructures or future projects offers the opportunity to exploit multiple installation synergies in the same limited space. At the same time, it possesses some important issues that need to be adequately addressed and solved for a reliable, efficient and safety operation of the installations within the common structure. High voltage (HV) and extra HV (EHV) cable lines boast a large number of installations, even though systematic theoretical and applied studies on the 'power cables- transport infrastructure' synergy have been carried out only for specific connections. In this paper both the HV direct current (HVDC) and HV alternate current (HVAC) cable technologies have been considered. For the sake of completeness, the gas insulated lines (GILs) have been considered as well, although they have a technological maturity lesser than the cable systems.

\section{2 'Power cables - transport infrastructures' forerunner researches}

The state-of-the-art of cable technologies and their power transmission performances are reported in several scientific publications in the recent literature [1-7].

In the last ten years the use of such technologies in railway and motorway infrastructures has been investigated by means of feasibility studies on projects which dealt with the realisation of interconnections between countries in Europe $[7,8]$. The studies, funded by the European Commission under the TEN-E program are:

- 2005-E204/05-TREN/05/TEN-E-S07.59331 ('Studies for a new $400 \mathrm{kV}$ HVDC interconnection between France and Italy: Integration of Electricity and Rail Transport in the Lyon-Turin High Speed Railway French-Italian Tunnel' (2005)) [8].

- TREN/2002/5.7100/Z/02-006 ('Studies for a new $380 \mathrm{kV}$ transmission line between Italy and Austria trough the Brenner Pass: Integration of Electricity and Rail Transport in Tunnel' (2002)) $[9,10]$.
These studies have allowed identifying and studying some issues related to the integration of power transmission lines in transport infrastructures.

It is worth noting that the mindset triggered by these studies has, in some way, facilitated the formation of two Cigrè working groups, whose technical brochures (TBs) have already been published:

- Cigré joint working group B3/B1-09: 'Application of long high capacity GILs in structures' [11].

- Cigré working group B1-08: 'Cable systems in multi shared structures' [12].

The latter TB, in particular, suggests the following terminological differentiations:

- Single purpose structure: any continuous structure containing one or more power cable systems which permits the installation, replacement, renewal, maintenance or repair of the services without the necessity of making either an excavation or disruption to any other service. This implies the structure is traversable by people and in some cases by some sort of technology. It is also called 'specific structure'.

- Multi-purpose structure: any continuous structure containing either a power cable system or systems and other services which permits the installation, replacement, renewal, maintenance or repair of the services, without the necessity of making either an excavation or disruption to any other services. This implies that the structure is traversable by people and in some cases by some sort of technology. It should be noted that a structure originally constructed for a single purpose may become a multi-purpose structure at a later time.

- Shared structure: one of the two previous cases, when it is jointly used, owned or operated by several entities.

Therefore, it is evident that an 'integrated-procedural approach' transmission line-road/railway infrastructure is more necessary than ever.

In the following some studies concerning this synergy are presented. 


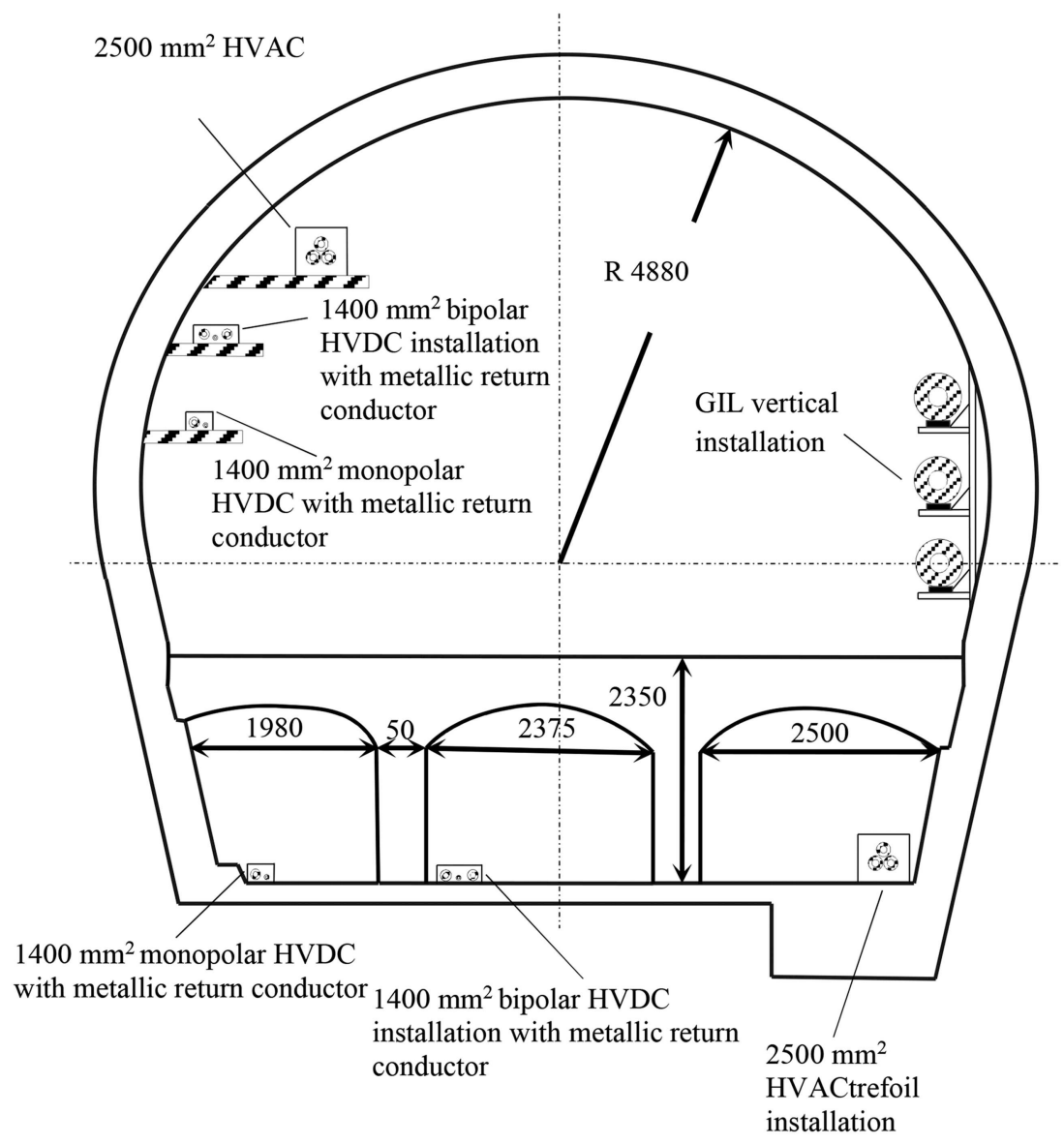

Fig. 1 Typical size of a highway tunnel (diameter $=9760 \mathrm{~mm}$ ) with power cables inside (all dimensions expressed in millimetres)

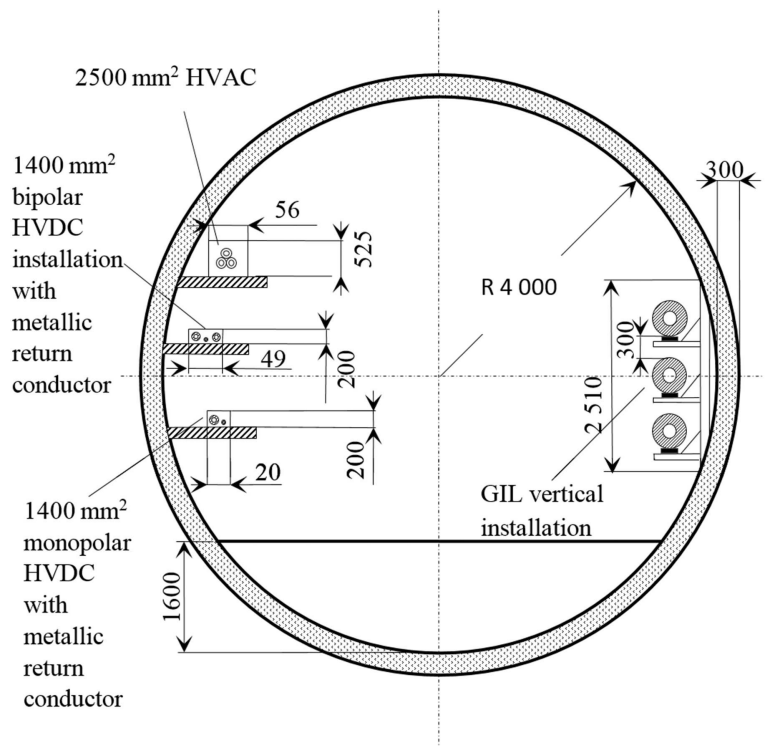

Fig. 2 Typical size of a railway tunnel (diameter $=8000 \mathrm{~mm}$ ) with power cables inside (all dimensions expressed in millimetres)

\section{Cable lines-transport infrastructure geometrical compatibility}

In multi-purpose structures, the congestion of the various available services can involve a significant space limitation for power cable installations.

Therefore, it is important to study the geometric compatibility between the structure and the cable lines, by carefully evaluating the cable encumbrance and the joints one, as well as the possibilities offered by the cable bending radii. Furthermore, installation time and space limitations (e.g. the laying of cables in motorway locations with traffic diverted on the disengaged roadway) possess specific constraints for both the laying machines encumbrances and the joint fixing and assembly procedures.

The same problem arises for the movement of the cable stretch in very long tunnels without intermediate accesses or with intermediate accesses which are away from each other.

In this regard, it is essential to identify, for each power transmission technology, which are the minimum encumbrances on the basis of the cable arrangements.

As an example, Figs. 1-3 show some scale drawings which represent the typical section dimensions of a highway tunnel, a railway tunnel and a railway prospection tunnel, respectively.

Inside these structures, several power transmission systems, installed with different arrangements, are shown. It is worth highlighting that these drawings do not represent clearly an installation proposal. Regarding the railway infrastructures, it is worth noting that this paper does not consider the possibility to transmit power through the catenary system, because in the authors' opinion the separation between transmission system and railway supply are better in order to increase the availability of the two systems.

Their purpose is to give the reader an immediate and clear idea of the comparative encumbrances of different transmission systems hosted into the structures.

In Figs. 1-3 the cable joints have not been represented.

\section{Multi-conductor cell analysis (MCA) approach representing power transmission systems hosted in structure}

To correctly represent and analyse the synergy and the electromagnetic interaction between power transmission lines and transport infrastructures which host other services, it is necessary to know the exact voltage and current in every conductive element of the power transmission line, without introducing simplifying hypotheses. In fact, in order to correctly calculate, for example, the induced voltage in metallic facilities inside the infrastructure or the magnetic fields generated by the line in different zones of the 


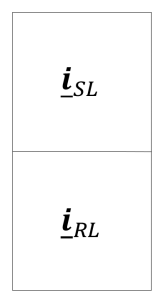

$\underline{\boldsymbol{i}}_{L \Delta}$

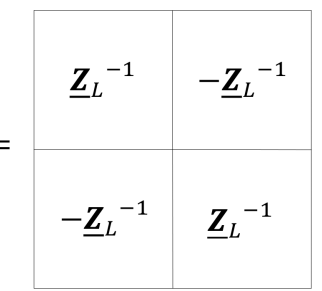

$\underline{\boldsymbol{Y}}_{L \Delta}$

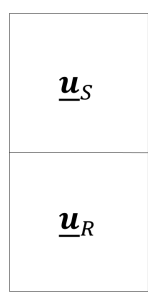

$\underline{\boldsymbol{u}}_{\Delta}$ infrastructure, the contribution of all the circulating currents in the transmission line (i.e. both the phase conductors and the screen/ enclosure currents) must be known. In this section, a multiconductor matrix approach is briefly described.

First, let us consider a single-circuit cable line composed of three single-core cables. It forms a multi-conductor system of $n=6$ conductors (three phases and three screens) parallel to themselves and to the ground. If a double-circuit cable line is considered, $n=$ 12. If the line is hosted within a structure, it is necessary to consider the electromagnetic interaction between the power line and the structure internal steel reinforcement (if any) by adding a new equivalent conductor in the considered multi-conductor system. The same procedure can be used if it is necessary representing the inductive coupling between the line and a passive metallic facility parallel with it. Therefore, $n$ could be equal to 12 or 13 and so on. As stated above, the whole multi-conductor system formed by a double-circuit cable line inside a tunnel, may be represented as a cascade of $m$ elementary cells of length $\Delta \ell$ (suitably chosen, i.e. ranging between 100 and $300 \mathrm{~m}$ ), modelled by a lumped PI-circuit (see Fig. 4) where the voltage column vectors $\boldsymbol{u}_{\mathrm{S}}, \boldsymbol{u}_{\mathrm{R}}$ and the current column vectors $\boldsymbol{i}_{\mathrm{S}}, \boldsymbol{i}_{\mathrm{SL}}, \boldsymbol{i}_{\mathrm{ST}}, \boldsymbol{i}_{\mathrm{R}}$ have a number of elements equal to $n$. Being that $\Delta \ell$ is sufficiently small (neglecting the border effects), it is possible to lump the uniformly distributed shunt admittances at both ends of the cell (transverse blocks $T S$ and $T R$ ) and to consider separately the longitudinal elements in the block $L$ (where $\boldsymbol{i}_{\mathrm{RL}} \equiv \boldsymbol{i}_{\mathrm{SL}}$ ). The exact expressions for earth-return impedances of buried conductors were first derived by Pollaczek [13] whereas those of overhead ones by Carson [14]. The presence of a non-homogeneous earth impedance can be taken into account as well [15]. As it has been recognised in literature [16], for buried conductors, the two approaches give the same results at harmonic frequencies. At power frequency, self and mutual

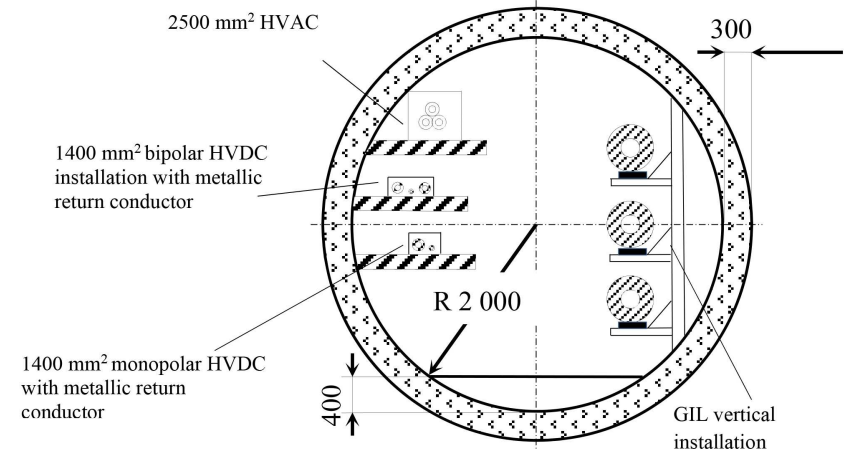

Fig. 3 Typical size of a railway prospection tunnel (diameter $=4000 \mathrm{~mm})$ with power cables inside (all dimensions expressed in millimetres)

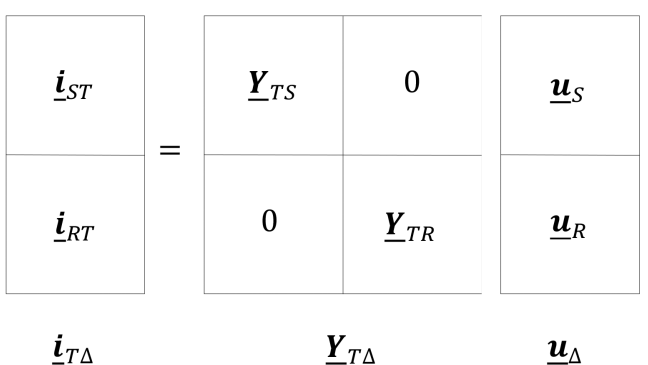

longitudinal impedances, which account for the earth return currents, can be obtained by applying the simplified or the complete Carson's theory or Wedepohl's theory [17], which gives approximated expressions of Pollaczek's formulae. By considering that:

$$
\begin{aligned}
& \underline{\boldsymbol{i}}_{\mathrm{S}}=\underline{\boldsymbol{i}}_{\mathrm{SL}}+\underline{\boldsymbol{i}}_{\mathrm{ST}} ; \quad \underline{\boldsymbol{i}}_{\mathrm{R}}=\underline{\boldsymbol{i}}_{\mathrm{RL}}+\underline{\boldsymbol{i}}_{\mathrm{RT}} ; \quad \underline{\boldsymbol{i}}_{\mathrm{SL}}+\underline{\boldsymbol{i}}_{\mathrm{RL}}=0 ; \quad \underline{\boldsymbol{u}}_{\mathrm{S}} \\
& -\underline{\boldsymbol{u}}_{\mathrm{R}}=\underline{\boldsymbol{Z}}_{\mathrm{L}} \cdot \underline{\boldsymbol{i}}_{\mathrm{SL}}
\end{aligned}
$$

being $\boldsymbol{Z}_{\mathrm{L}}$ non-singular, it is possible to infer the vectors of the shunt currents at sending-end $\underline{\boldsymbol{i}}_{\mathrm{ST}}$ and at receiving-end $\underline{\boldsymbol{i}}_{\mathrm{RT}}$ by the above matrix relations.

$\underline{\boldsymbol{Y}}_{\mathrm{TS}}$ and $\underline{\boldsymbol{Y}}_{\mathrm{TR}}(n \times n)$ can be computed by taking into account the shunt capacitive and conductive links. The self and mutual admittances of half-cell are considered by suitably arranging the following formulae:

$$
\begin{aligned}
& \underline{\boldsymbol{y}}_{1}=g_{1}+j \omega c_{1}=\frac{\omega \cdot 2 \pi \cdot \varepsilon\left(\tan \delta_{1}+j\right)}{\ln \left(r_{2} / r_{1}\right)}[\mathrm{S} / \mathrm{km}] ; \\
& \underline{\boldsymbol{y}}_{1}=g_{2}+j \omega c_{2}=\frac{\omega \cdot 2 \pi \cdot \varepsilon\left(\tan \delta_{2}+j\right)}{\ln \left(r_{4} / r_{3}\right)}[\mathrm{S} / \mathrm{km}]
\end{aligned}
$$

in which (see Fig. 5) $g_{1}$ and $g_{2}$ represent the leakage conductances across inner and outer insulations, $\varepsilon_{1}, \varepsilon_{2}$ and $\tan \delta_{1}, \tan \delta_{2}$ the corresponding dielectric constants and loss factors, respectively.

The superimposition of $\underline{\mathbf{Y}}_{L \Delta}$ and $\underline{\boldsymbol{Y}}_{T \Delta}$ yields:

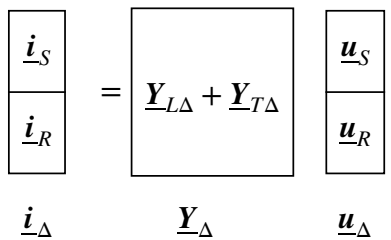

Once $\underline{\boldsymbol{Y}}_{\Delta}$ has been computed, it is necessary to achieve the admittance matrix $\underline{Y}$ of the whole multi-conductor system. Let us take as an example the system shown in Fig. 6 (where $S_{g}, S_{0}, S_{1}, \ldots$, $S_{L}$ indicate the sections or ports) in which, for convenience in the calculation, the conductors are numbered $1-6$, the screens $7-12$ and the hosting structure 13 . The first cable will have conductor 1 and sheath 7, etc. The creation of $\underline{Y}$ involves all the matrices in Fig. 6 starting from the left side [18]: the equivalent supply matrix $\underline{\boldsymbol{Y}}_{\mathrm{Aph}}$ $(6 \times 6)$, the double-circuit sending-end matrix $\underline{\underline{Y}}_{\mathrm{S}}$, the cell matrices $\underline{\boldsymbol{Y}}_{\Delta i}$, the double-circuit receiving-end matrix $\underline{\boldsymbol{Y}}_{\mathrm{R}}$ and the matrix $\boldsymbol{Y}_{\text {Load }}(3 \times 3)$.

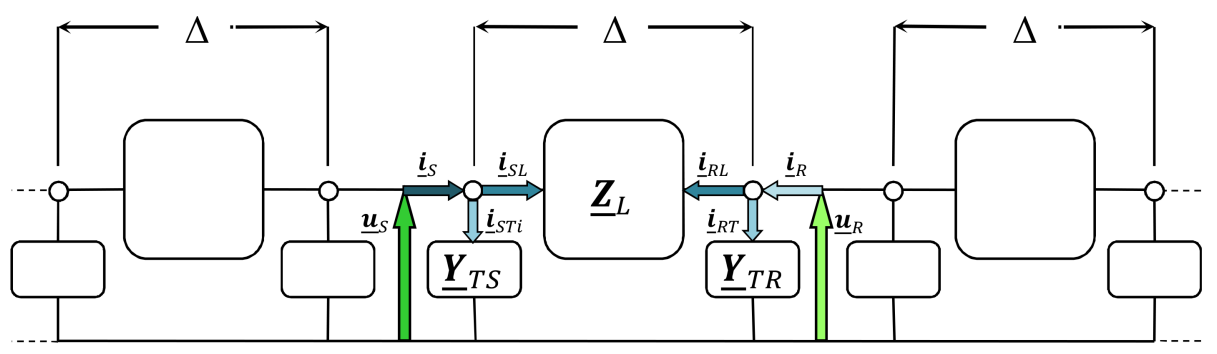

Fig. 4 Elementary cell cascade for single-circuit cable line modelling 

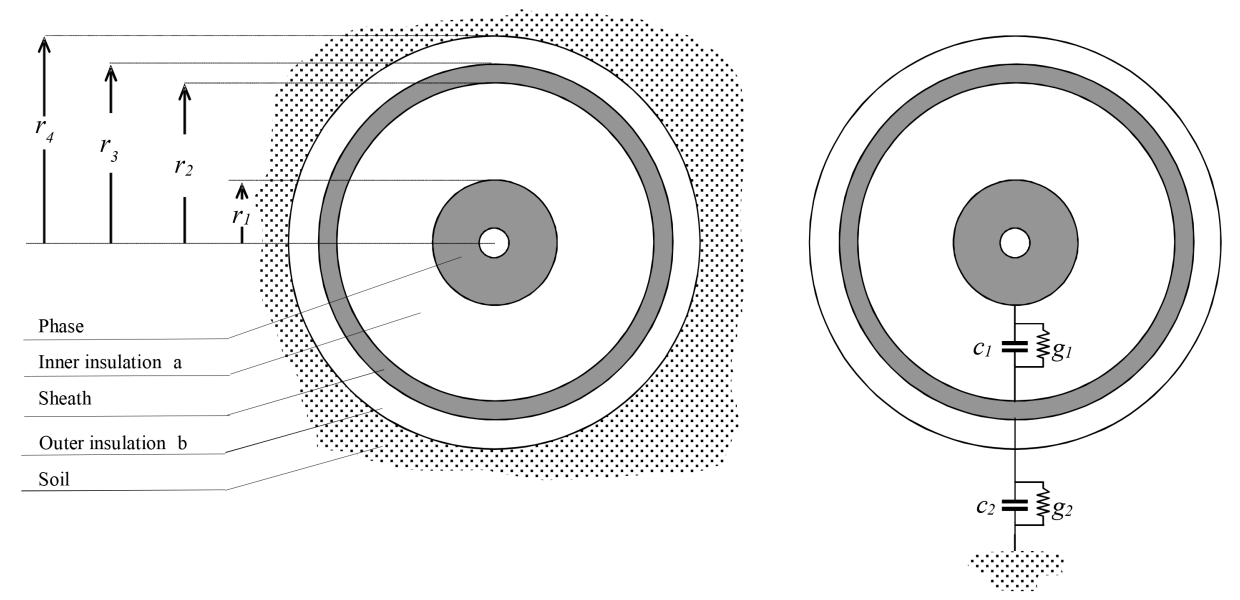

Fig. 5 Scheme for the computation of shunt admittances
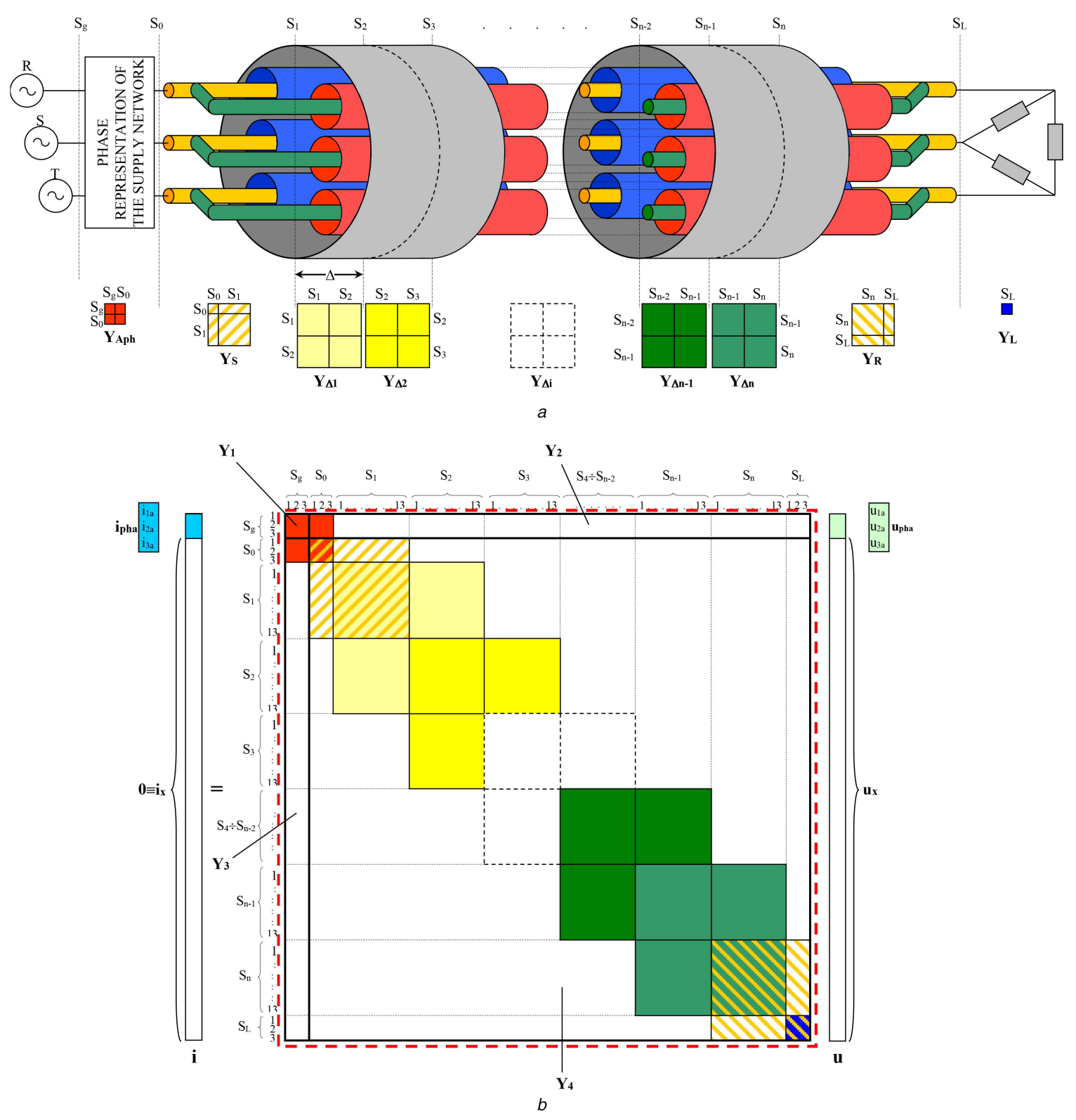

Fig. 6 Creation of $\underline{\boldsymbol{Y}}$ and its structure

(a) Double circuit cable line hosted in a structure and matrix representation of its elements, (b) $\boldsymbol{Y}$ matrix structure

$\underline{Y}$ is calculated by using automatic topological procedures that give rise to partial superposition of matrices as in Fig. $6 b$ ) which can be easily managed because of it is structurally sparse. For the system of Fig. $6 a$ ) the general equation

$$
\underline{i}=\underline{Y} u
$$

can be partitioned as in Fig. 6b) (where the whole matrix $\underline{Y}$ is framed by a dotted red square). Noting that only $\underline{\underline{i}}_{\text {pha }}$ is a non-zero current vector and that $\underline{i}_{x}=0$, it yields: 


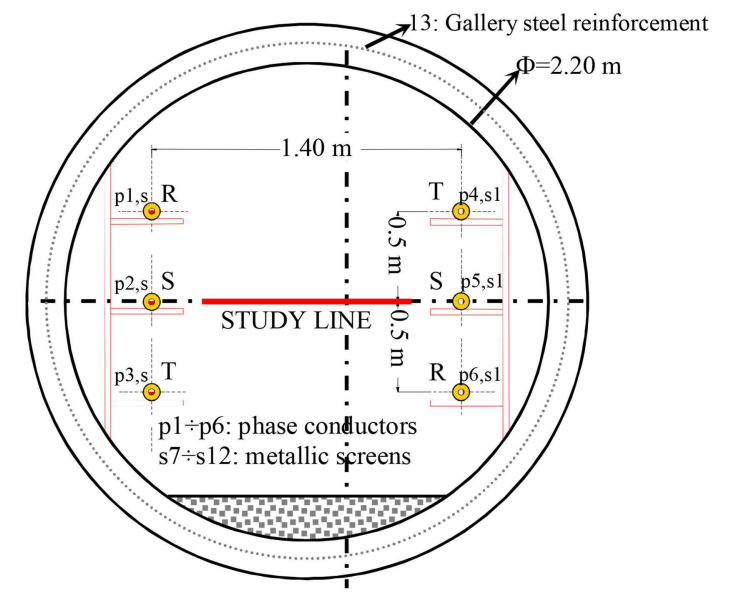

Fig. 7 AC double circuit cable line within a single purpose tunnel

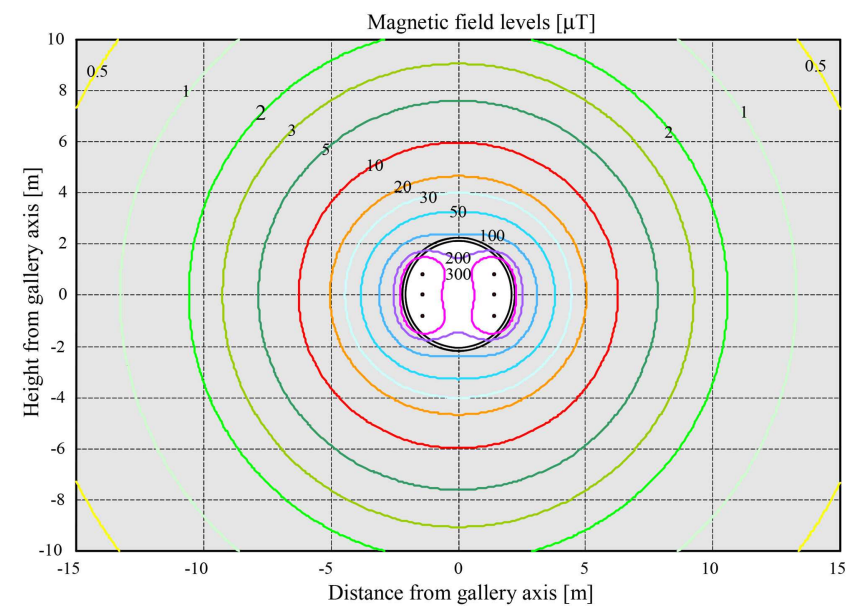

Fig. 8 Magnetic induction levels inside the tunnel with $I=1443$ A for circuit (cross-bonding with phase transpositions)

$$
\underline{\boldsymbol{i}}_{x}=0=\underline{\boldsymbol{Y}}_{3} \underline{\boldsymbol{u}}_{\mathrm{pha}}+\underline{\boldsymbol{Y}}_{4} \underline{\boldsymbol{u}}_{x},
$$

and thus

$$
\underline{\boldsymbol{u}}_{x}=-\underline{\boldsymbol{Y}}_{4}^{-1} \underline{\boldsymbol{Y}}_{3} \underline{\boldsymbol{u}}_{\mathrm{pha}},
$$

where $\underline{\boldsymbol{Y}}_{4}$ is not singular. Therefore, by knowing all the subvectors

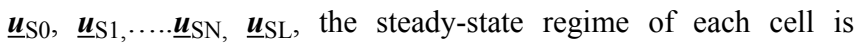
completely available. In this way all the electrical quantities are known for each cell length. It is worth noting that, once supplied by a positive sequence voltage vector, the system results entirely determined at a circuit level and is solved directly without iterations. In particular, this method can be used as an in-depth analysis in order to verify possible simplifying hypotheses introduced by other methods.

It is worth mentioning that the described approach is suitable to take into account the skin effect in Milliken type cables [19] or the use of power line carrier applied to electrical networks [20] and to represent power transmission overhead lines as well [21].

\section{Electromagnetic fields and compatibility}

A multi-purpose structure, as already mentioned, has multiple services in a common area. Therefore, electromagnetic compatibility among the different installations plays a key role. The induced voltages on metallic parts located in parallel must be studied both in steady state and in fault conditions. In case of the primary infrastructure function was the railway transport, with an $\mathrm{AC}$ feeding system (as in case of the Italian high-speed system $2 \times$ $25 \mathrm{kV}$, frequency $=50 \mathrm{~Hz}$ ) it is necessary to verify the electromagnetic interferences by considering the railway system as the inducting one (in EMI jargon known as 'killer'), and the power transmission line as the inducted one (in EMI jargon known as 'victim') [22]. There are many factors that influence the magnitude of the magnetic field in proximity to the power cables, such as the spacing between them, the laying system, (the laying depth in case of underground systems) and of course the circulating current phasors in the power line. Nevertheless, as a result of several simulations, carried out by considering power cables and GIL installed in different structures, it is possible to infer that the different transmission systems can be indicatively classified on the basis of their typical generated magnetic fields.

\subsection{AC systems}

Concerning the magnetic field generated by AC lines, it is worth noting that several State Authorities impose restrictions on the maximum magnetic field exposures. For example, in Italy the maximum exposure limit is $100 \mu \mathrm{T}$. The value of attention for long term exposure is $10 \mu \mathrm{T}$ for the existing transmission lines and $3 \mu \mathrm{T}$ for the new ones. In Switzerland the new power transmission line installations have to respect the limit of $1 \mu \mathrm{T}$ for long term exposure.

5.1.1 HVAC insulated cables: The HVAC technology presents a high external magnetic field in proximity to the cables themselves and a very reduced one as moving away from them (the external electric field is null since metal screens are always earthed, at least, at one end). The reasons of this behaviour lie in the bonding configurations of screens. The magnetic fields generated by the screen induced currents could imply a decrease of the magnetic field produced by phase conductors. It is worth remembering that by using the cross-bonding configuration of the screens, the screen currents are subject to a drastic reduction, with the benefit of the power loss reduction but, at the same time, with the detriment of the magnetic field screening. The simulation results highlight, for $400 \mathrm{kV}$ transmission lines with a transmitted power of $1000 \mathrm{MVA}$ per circuit, magnetic induction magnitudes of $100 \mu \mathrm{T}$ in the close proximity to the cables. Induction magnitudes in the order of $10 \mu \mathrm{T}$ are detectable at a distance greater than $4 \mathrm{~m}$ from the cables. Therefore, from an electromagnetic standpoint, the HVAC technology is more suitable for installations in dedicated infrastructures rather than in multi-purpose galleries. In fact, electromagnetic interferences with other systems sited in parallel to the power lines are foreseeable, by excluding the possibility of maintenance works in these systems if the cable line is under voltage. A possible application for EHV AC cables in structures is the one presented in Fig. 7: it is very similar to that of Berlin [1], Barajas [2] and London [3], i.e. a double circuit cable line into a dedicated tunnel. By assuming that the cable screens are crossbonded and the phases are transposed [4], Table 1 shows the current phasors calculated by means of MCA (six phases six plus six screens as it is shown in Fig. 7). As it is known, the phase sequence is the one which minimises the external magnetic field, i.e. RST-TSR (often called 'low reactance' supplying in technical literature). The screen current phasor values show that the crossbonding with phase transpositions allows eliminating the circulating currents (only the minor section capacitive currents remain): it is worth remembering that such a big drastic elimination of induced currents may be difficult to get in real installations, due to the cable route constraints which often do not allow to have equal 'minor sections'. Fig. 8 shows the magnetic induction values in the above mentioned hypothesis. The values decrease very rapidly as one moves away from the tunnel. In shallow underground structures (e.g. $2 \mathrm{~m}$ in the installation of the airport 'Barajas' [2]), the magnetic flux density at $1 \mathrm{~m}$ above the ground level is lower than $100 \mu \mathrm{T}$.

Fig. 9 shows the magnetic induction values into the tunnel along the study line of Fig. 6: in this case, in the proximity of the cables, high values are reached, (the possible shielding effect of the screens is cancelled by the cross-bonding, which is necessary in order to achieve a high transmission power). Hence, the person access for maintenances must be done at reduced load or with the power lines de-energised. It is worth remembering that in case of strong limitations to the magnetic field magnitudes, it is possible to 


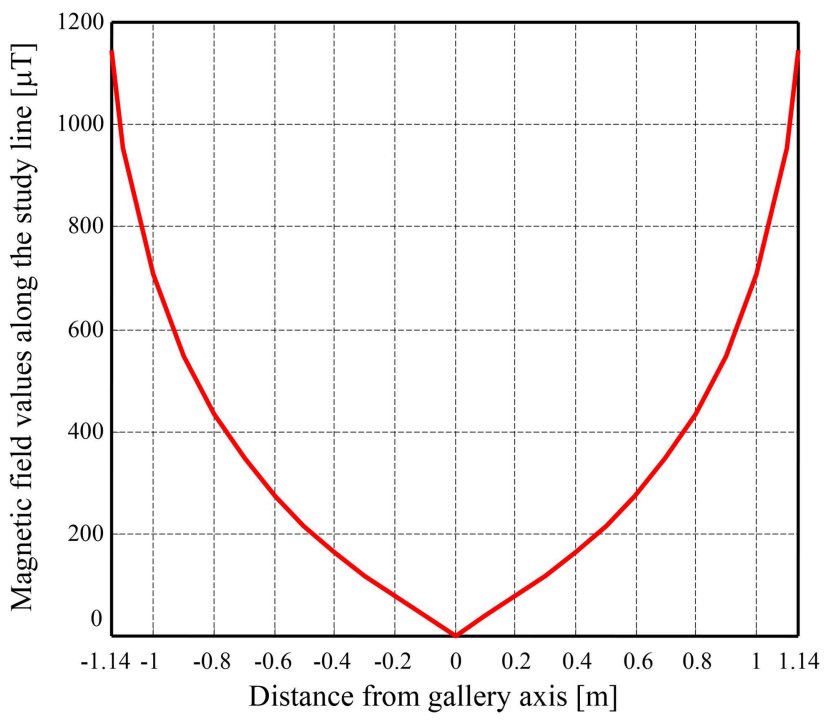

Fig. 9 Magnetic induction levels within the tunnel along the study line of Fig. 6 with $I=1443$ A for circuit (cross-bonding with phase transpositions)

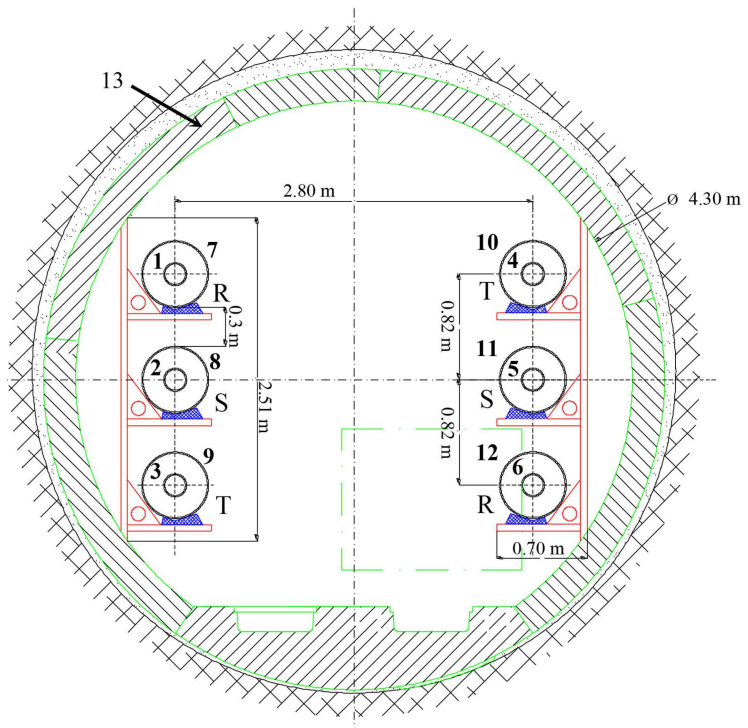

Fig. 10 GIL double circuit installation within a railway prospection tunnel

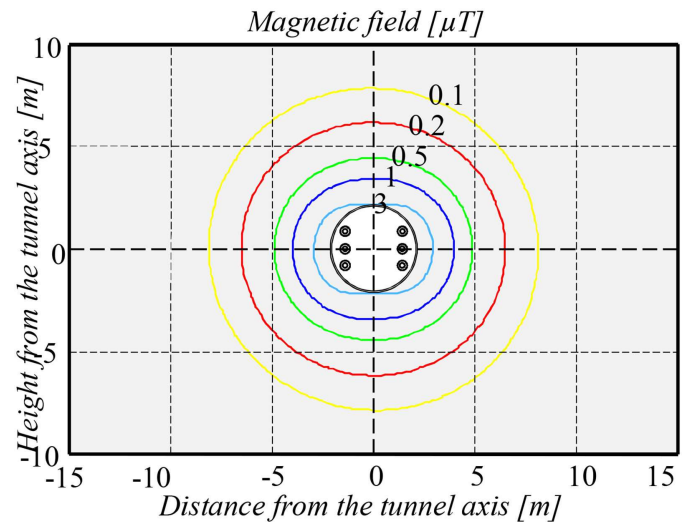

Fig. 11 Magnetic field magnitude by neglecting proximity effects, with $S$ $=2000 \mathrm{MVA}$

use suitable mitigation systems, with possible derating on the cable ampacity [23-28].

5.1.2 Gas insulated lines: An electrical energy transmission line constituted by GIL is characterised by a very low external magnetic field (the external electric field is null because the aluminium enclosure is earthed through the solid-bonding
Table 1 Current phasors $[A]$ in the multi-conductor system of Fig. 6 for the calculation of the magnetic induction

\begin{tabular}{lcccc}
\hline \multicolumn{2}{c}{ Phase conductors: $\mathrm{p} 1 \div \mathrm{*} 6$} & \multicolumn{2}{c}{ Metallic screens: $\mathrm{s} 7 \div \mathrm{s} 12$} \\
\hline $\mathrm{R}$ & $p 1$ & $|1443| \angle 104^{\circ}$ & $s 7$ & $|15.6| \angle-105^{\circ}$ \\
$\mathrm{S}$ & $p 2$ & $|1443| \angle-16^{\circ}$ & $s 8$ & $|15.8| \angle 138^{\circ}$ \\
$\mathrm{T}$ & $p 3$ & $|1442| \angle-136^{\circ}$ & $s 9$ & $|16.5| \angle 16^{\circ}$ \\
$\mathrm{T}$ & $p 4$ & $|1443| \angle-136^{\circ}$ & $s 10$ & $|16.5| \angle 16^{\circ}$ \\
$\mathrm{S}$ & $p 5$ & $|1443| \angle-16^{\circ}$ & $s 11$ & $|15.8| \angle 138^{\circ}$ \\
$\mathrm{R}$ & $p 6$ & $|1443| \angle 104^{\circ}$ & $s 12$ & $|15.6| \angle-105^{\circ}$ \\
\hline
\end{tabular}

connection). Several simulations related to a $400 \mathrm{kV}$ GIL installation into multi-purpose galleries, have shown magnetic induction levels of $10 \mu \mathrm{T}$ in the proximity to the ducts, which are reduced to $3 \mu \mathrm{T}$ at $2 \mathrm{~m}$ away from the transmission line. These values are definitely under the $100 \mu \mathrm{T}$ exposure limit and this evidence allows defining GIL as totally compatible with the installation in a multi-purpose structure from an electromagnetic standpoint. The reason of this result lies in the low resistance of the GIL aluminium enclosures (which are solidly bonded), which permits having circulating return currents almost equal to the ones of the phase conductors. The sum of the magnetic fields produced by these two current phasors, which have almost the same magnitude but opposite angles, is reflected in a very low resultant magnetic induction: this implies negligible electromagnetic interferences. Moreover, the GIL enclosures have an effective screening action against external magnetic interferences as well. With reference to a railway tunnel equipped with a prospection tunnel, Fig. 10 presents the case of a $400 \mathrm{kV}$ double circuit GIL, with a transmitted power equal to 1000 MVA per circuit and a power factor of 0.98 installed in the prospection tunnel. The considered GIL arrangement is the vertical one, with spacing equal to $2.8 \mathrm{~m}$, with a 'low-reactance' feeding (R-S-T-T-S-R), as it is shown in Fig. 11.

By means of the MCA approach [18] the current phasors have been calculated by taking into account not only the GIL phase conductors and enclosures but an additional conductive layer as well, represented by the tunnel steel reinforcement (it has been assumed that the enclosures are connected at given length intervals to the tunnel steel reinforcement). Table 2 shows the current phasors in the receiving end section of the line, by considering the proximity effect, although this effect appears negligible because of the low external magnetic field. It is worth remembering that the minimum distance between two GIL ducts is about $0.3 \mathrm{~m}$ in order to allow using the orbital welding. The spatial distribution of magnetic flux density outside and inside the tunnel, by neglecting the proximity effects, is reported in Fig. 10.

\subsection{Direct current systems}

It is well known that in presence of static electromagnetic fields, which are typical of HVDC cables, there is no possibility of any magnetic induction, but it has been extensively studied the role played by the harmonics, which are present on the line and which are generated by the converter stations, and their possible magnetic interferences. By means of a collaboration between the University of Padova and Prysmian Power Link, it has been developed a model [29] which allows studying the HVDC cables behaviour for different harmonic frequencies. The study demonstrated that, at harmonic frequencies, the HVDC cables behave like a coaxial cable, without giving, in fact, any electromagnetic interferences. Therefore, they do not involve any risk in road/railway infrastructure installations, where a certain closeness between systems of different nature is expected. With regard to the static magnetic fields generated by D.C. electric lines, there is no reference standards which prescribe exposure limits. Nevertheless, a European Council Recommendation (dated 12/07/1999) sets the value of $40 \mathrm{mT}$ in the frequency range from 0 to $1 \mathrm{~Hz}$.

This recommendation reflects the ICNIRP (International Commission on Non-Ionizing Radiation Protection) guidelines (see Table 3). 
Table 2 Current phasors for a double-circuit GIL (400 kV, $S$ $=2000 \mathrm{MVA}, \cos \phi=0.98$ )

Receiving end currents, $A$

\begin{tabular}{llccc} 
& \multicolumn{2}{c}{ Phases } & \multicolumn{1}{c}{ Enclosures } \\
\hline $\mathrm{R}$ & 1 & $|1442| \angle-4^{\circ}$ & 7 & $|1423.4| \angle 169^{\circ}$ \\
$\mathrm{S}$ & 2 & $|1442| \angle-124^{\circ}$ & 8 & $|1441.7| \angle 49^{\circ}$ \\
$\mathrm{T}$ & 3 & $|1442| \angle 116^{\circ}$ & 9 & $|1460.1| \angle-71^{\circ}$ \\
$\mathrm{T}$ & 4 & $|1442| \angle 116^{\circ}$ & 10 & $|1460.1| \angle-71^{\circ}$ \\
$\mathrm{S}$ & 5 & $|1442| \angle-124^{\circ}$ & 11 & $|1441.7| \angle 49^{\circ}$ \\
$\mathrm{R}$ & 6 & $|1442| \angle-4^{\circ}$ & 12 & $|1423.4| \angle 169^{\circ}$ \\
\multicolumn{2}{l}{ tunnel steel reinforcement } & 13 & $|37.3| \angle 144^{\circ}$ \\
\hline
\end{tabular}

Table 3 Static magnetic field exposure limits

\begin{tabular}{lc}
\hline $\begin{array}{l}\text { Magnetic field exposure } \\
\text { characteristics }\end{array}$ & $\begin{array}{c}\text { D.C. magnetic induction } \\
\text { values }\end{array}$ \\
\hline continuous exposure & $40 \mathrm{mT}$ \\
whole work day (time-weighted & $200 \mathrm{mT}$ \\
average) & \\
ceiling value & $2 \mathrm{~T}$ \\
limbs & $5 \mathrm{~T}$ \\
\hline
\end{tabular}

Table 4 Transmission technology classifications based on the generated magnetic field and electromagnetic interference

\begin{tabular}{lcc}
\hline Technology & $\begin{array}{c}\text { Magnetic field } \\
\text { level }\end{array}$ & Interferences \\
\hline $\begin{array}{l}\text { cross bonded } \\
\text { HVAC insulated } \\
\text { cable }\end{array}$ & $\begin{array}{c}\text { high nearby the } \\
\text { cables screening } \\
\text { with possible } \\
\text { derating }\end{array}$ & $\begin{array}{c}\text { possible magnetic } \\
\text { interferences }\end{array}$ \\
$\begin{array}{l}\text { HVDC insulated } \\
\text { cable }\end{array}$ & $\begin{array}{c}\text { comparable with } \\
\text { earth magnetic field }\end{array}$ & $\begin{array}{c}\text { electromagnetic interference } \\
\text { due to harmonics are } \\
\text { negligible due to the } \\
\text { screening effect of the metal } \\
\text { screens }\end{array}$ \\
sC GIL & very low & $\begin{array}{c}\text { negligible due to the } \\
\text { enclosure screening effects }\end{array}$ \\
\hline
\end{tabular}

The values for different types of exposure are reported in Table 4. It is important to note that electronic devices, such as cardiac pacemakers, could be not protected by the magnetic field limits given in Table 3 .

In general, cardiac pacemakers should avoid magnetic field exposures exceeding $0.5 \mathrm{mT}$. By assuming $I=1000 \mathrm{~A}$ for pole, the magnetic induction levels at different heights, above and below the $\mathrm{x}$-axis of Fig. 12 and inside and outside the tunnel (magnetic isoflux lines) are shown in Figs. 13 and 14 respectively.

A possible application is shown in Fig. 12, where a bipolar HVDC transmission line (two pole cables and a metallic return) has been hosted inside a multi-purpose railway tunnel.

The magnetic induction levels are extremely low (this is due to the closeness, about $0.5 \mathrm{~m}$, between the magnetic field sources which are affected by currents, which are equal and opposite) and rapidly decline as the distance from the y axis of Fig. 12 increases. In Fig. 13, the grey zone represents the area, which the train transit concerns. In Fig. 14, the black circle represents the tunnel profile: the magnetic induction varies from $500 \mu \mathrm{T}$ (in proximity to the pole cables) to about $2 \mu \mathrm{T}$ and, within a possible railway wagon, from about 20 to $2 \mu \mathrm{T}$. With the purpose to understand the order of magnitude of the magnetic induction generated by the HVDC system, it is worth remembering that the static magnetic field of the Earth varies between 30 and $70 \mu \mathrm{T}$, depending on the geographical location. Table 4 presents the conclusions derived by several analyses and a useful guide in order to understand the electromagnetic compatibility between power lines and other services, which are present in transport infrastructures.

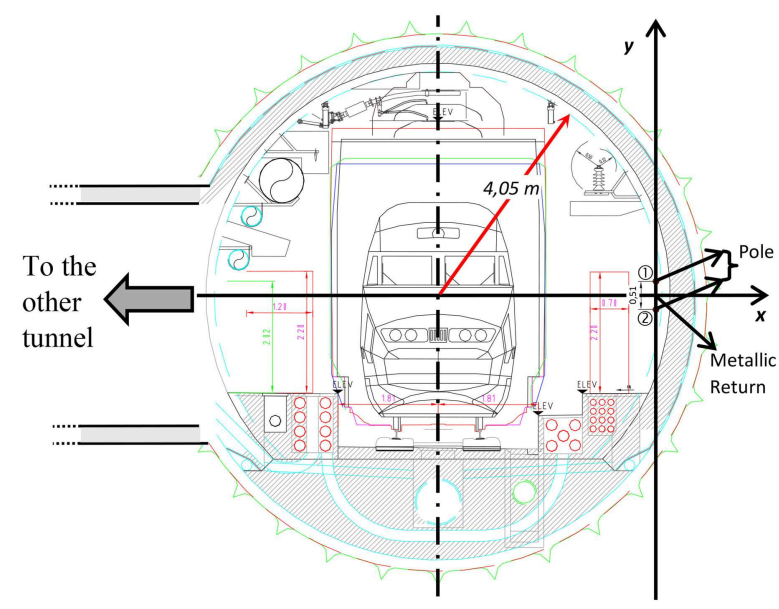

Fig. 12 Bipolar HVDC cable line with metallic return conductor within a railway tunnel

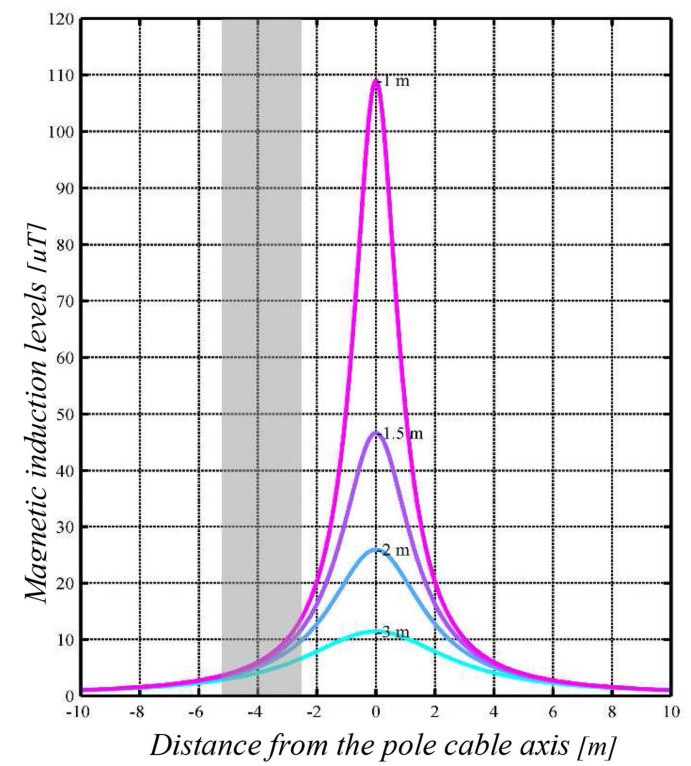

Fig. 13 Magnetic induction levels at different heights above and below the $x$-axis

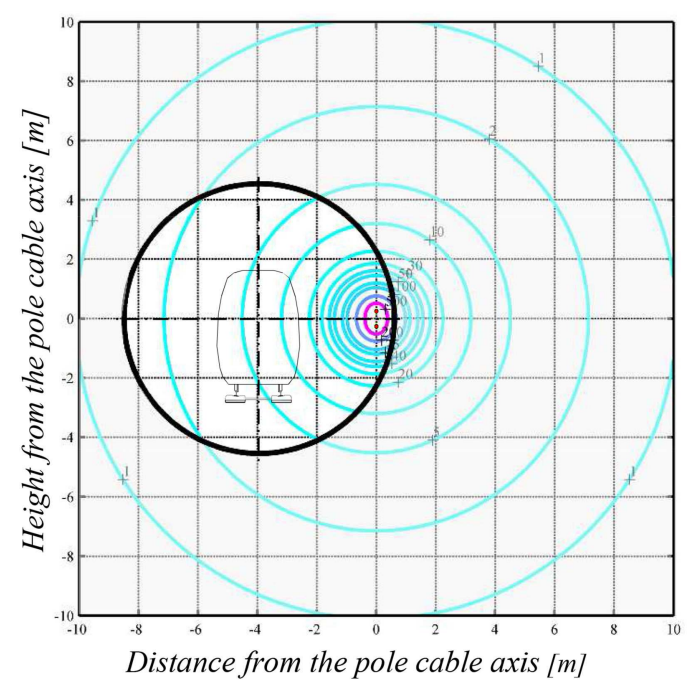

Fig. 14 Magnetic induction levels inside and outside the tunnel

\section{External effect of a possible phase-to-screen short circuit inside the hosting structure}

The possible closeness between a power transmission line and other different services within transport infrastructures requires the 
study of the 'external effect' of a possible (but unlikely) phase-toscreen fault in the cable line. The cable short circuit effect is significantly different depending on whether the line is a HVAC system or a HVDC one. In the following, some indicative considerations are presented, in the uncertainty of some variables regarding the electric arc behaviour: the aim is to give the reader a formalised explanation of the cable failure phenomena, which, however, need to be experimentally verified.

\subsection{Insulated cables}

With regard to the AC power transmission, the value of the single phase short-circuit current value depends on the transmission network node [30-32] where the fault occurs, and upon the weakness or strength of the supplying network. Its magnitude, in comparison with the three-phase symmetrical short-circuit current, depends on the neutral wire connection (quantifiable as a function of the ratio between the positive sequence sub-transient reactance and the zero sequence one). The fault duration time can be identified within a predictable interval whose boundaries correspond to the intervention in the first and in the second step of distance relays, reported in Table 5.

As already mentioned, the arc voltage parameter is the most difficult to determine.

In any case, by assuming $I_{\mathrm{sc}, 1-f}=40 \mathrm{kA}, U_{\mathrm{a}}=1 \mathrm{kV}$ and $t=0.3$ $\mathrm{s}$, the released energy from the short circuit would be:

$$
E_{\mathrm{A} . \mathrm{C} .}=U_{\mathrm{a}} \cdot I_{\mathrm{cc}, 1-f} \cdot t=1000 \cdot 40000 \cdot 0.3=12 \mathrm{MJ}
$$

The arc voltage $U_{a}$ can be even greater than the one assumed in (1). Some EDF (French transmission system operator) measurements have provided values up to $2 \mathrm{kV}$, which is twice compared to the one calculated in (1). In confirmation of these assessments, paper [33] reports the disastrous effects of a phase-toscreen short-circuit for an AC cable line. In particular, it has been observed, for all the examined cases, extensive damages to the healthy phases, propagation of fire and gas emissions in the surrounding environment. These results suggest the idea of using protective shields for the cables with sufficient volume to allow the circulation of the emitted gas flow, by deviating it, in order to obtain a gas pressure decrease. Besides, it is also convenient to evaluate the minimum distance between the cables, in order to preserve, in case of failure, the healthy phases. As regards the D. C. transmission, it is useful to remember that a short circuit resulting from the failure of the cable insulation is partly fed by the energy stored in the cable and partly by the energy that comes from the AC network, through the power conversion stations. In any case, the fault current does not exceed $2 \div 3$ times the cable rated current for a time which is comprised between 10 and $20 \mathrm{~ms}$. By means of an approximate calculation, it is possible to compute the shortcircuit released energy by considering only the cable capacitance effect. By assuming a line length $L=100 \mathrm{~km}$, a voltage $U_{n}=400$ $\mathrm{kV}$ with a kilometric capacitance equal to $c=0.30 \mu \mathrm{F} / \mathrm{km}$, the released energy is equal to:

$$
E_{\mathrm{D} . \mathrm{C} .}=\frac{1}{2} \cdot c \cdot L \cdot U_{n}^{2}=2.4 \mathrm{MJ}
$$

which is a fifth of the magnitude calculated in (1) for the AC case. These arguments seem to be confirmed in some experiments carried out in the EDF laboratories of Les Renardières and presented in [8]: this paper shows failure external effects, which are consistent with the released energy approximately derived from (2). It is worth noting that long cables could have released energies much higher than the one calculated in (2).

\subsection{Gas insulated lines}

In case of AC GIL installation [34], the manufacturer must declare the rated short time withstand current related to a phase-toenclosure short circuit, in accordance with IEC 62271-204 [35] (a typical value is $50 \mathrm{kA}$ for $3 \mathrm{~s}$ ). A phase-to-enclosure fault occurrence can be caused, for example, by the presence of metallic
Table 5 Fault clearance times of distance relays on the

\begin{tabular}{|c|c|c|c|c|}
\hline \multirow[t]{2}{*}{$\begin{array}{l}\text { Voltage 380- } \\
220, \mathrm{kV}\end{array}$} & \multicolumn{2}{|c|}{$\begin{array}{l}\text { Fault clearance time } \\
\text { (faults near the } \\
\text { generator), ms }\end{array}$} & \multicolumn{2}{|c|}{$\begin{array}{l}\text { Fault clearance time } \\
\text { (faults far from the } \\
\text { generator), ms }\end{array}$} \\
\hline & $\begin{array}{l}\text { First } \\
\text { zone }\end{array}$ & $\begin{array}{l}\text { Second } \\
\text { zone }\end{array}$ & $\begin{array}{l}\text { First } \\
\text { zone }\end{array}$ & $\begin{array}{l}\text { Second } \\
\text { zone }\end{array}$ \\
\hline cables & 100 & 250 & 250 & 350 \\
\hline $\begin{array}{l}\text { GIS (gas } \\
\text { insulated } \\
\text { substation) }\end{array}$ & 100 & 250 & & \\
\hline
\end{tabular}
basis of the failure location

debris within the pipes during the assembly operations, from manufacturing defects or by damages caused during the transport operations. The effects of such a failure, given the released energies computed by means of (1) can lead to the evaporation and the subsequent perforation of the metal enclosure wall. This can consequently imply the risk of damaging the GIL pipes nearby or the other structures in the vicinity, insulating gas leakage and danger for people, which are present in the structure. The risk of fire propagation is null for a GIL line, as well as the development of combustion fumes, being the enclosures constituted by aluminium. The energy released by the short-circuit current is transmitted to the metal enclosure by conduction and thermal radiation. This energy may be expressed as:

$$
E_{c . a .}^{\prime \prime}=K^{\prime \prime} \cdot U_{\mathrm{arc}} \cdot I_{\mathrm{cclf}} \cdot \Delta t_{\mathrm{protez}}
$$

where $K^{\prime \prime}$ is a coefficient which represents the electrical energy portion which cause the enclosure fusion. The main factor which has to be taken into account for the safety of an AC GIL installation is the choice of the minimum enclosure thickness in order to avoid the enclosure perforation. On the basis of experimental test results, it is possible to identify a relationship between the thickness of the GIL metal enclosure and the time needed to melt it. The tests were carried out for the voltage levels of 154 and $275 \mathrm{kV}$ with arc voltages from 1 to $2 \mathrm{kV}$. The test time intervals were from 0.1 to $0.4 \mathrm{~s}$ for a $50 \mathrm{kA}$ current and from 1 to 4 $\mathrm{s}$ for a $2 \mathrm{kA}$ current. The used insulating gas was pure $\mathrm{SF}_{6}$ at 3.4 bar. The obtained relationship can be expressed as:

$$
t_{m}=K \cdot \frac{d^{2}}{I}[\mathrm{~s}]
$$

where, $t_{m}=$ time limit beyond which the enclosure fusion occurs [s]; $I=\operatorname{arc}$ current $[\mathrm{A}] ; d=$ the outer casing thickness $[\mathrm{m}] ; k$ is a parameter depending on the characteristics of the material and the arc voltage and its expression is reported in [34]. Therefore, by knowing the fault clearance time, it is possible to derive the safety enclosure thickness in order to avoid its fusion. It is worth noting that for GILs with $\mathrm{SF}_{6} / \mathrm{N}_{2}(20 \% / 80 \%)$ insulating gas, the arc foot enlarges so to lessen the arc energy in a single point.

\section{Reliability of synergy electric transmission and transport}

By considering the cable failure rate data from the Cigrè TB [36] for voltage values between $220 \div 500 \mathrm{kV}$, (reported in Table 6), it is worth considering that for power cables inside structures the proportion of the cable failure rate related to external origin is null. Since this component counts for $50 \%$ of the total failure rate, the cable arrangements within structures halves the cable failure rates.

\section{Conclusion}

The research field on the transport structures and HV and EHV power transmission line co-utilisation deserves to be investigated in all its engineering aspects (and it is worth considering the impact of power cable installations on the social costs [37]). The paper highlights that an integrated 'procedural approach' of this synergistic combination is necessary by means of the presented 
Table 6 Cable, joints and terminations failure rates for voltage between $220-500 \mathrm{kV}$ [36]

\begin{tabular}{|c|c|c|}
\hline Component & $\begin{array}{c}\text { Failure rate per } \\
\text { kilometre of circuit } \\
\text { (ctkm) }\end{array}$ & $\%$ \\
\hline $\begin{array}{l}\text { cable (internal fault + external } \\
\text { fault) }\end{array}$ & $\frac{\text { fault }}{(100 \mathrm{ctkm} \cdot \text { year })}$ & 0.133100 \\
\hline cable (internal fault) & & 0.06750 \\
\hline cable (external fault) & & 0.06750 \\
\hline $\begin{array}{l}\text { joint (internal fault + external } \\
\text { fault) }\end{array}$ & $\frac{\text { fault }}{(100 \mathrm{ctkm} \cdot \text { year })}$ & 0.04810 \\
\hline joint (internal fault) & & 0.02654 \\
\hline joint (external fault) & & 0.02246 \\
\hline $\begin{array}{l}\text { termination (internal fault + } \\
\text { external fault) }\end{array}$ & $\frac{\text { fault }}{(100 \mathrm{ctkm} \cdot \text { year })}$ & 0.050100 \\
\hline termination (internal fault) & & 0.03264 \\
\hline termination (external fault) & & 0.01836 \\
\hline
\end{tabular}

investigations and by identifying the optimal solution for each structure type. Such a systematic approach can significantly contribute to the progress of the electric transmission line installations in transport facilities. The results of this research can be used in the planning stages and in the operational management of power cables in existing or future infrastructures. A particularly significant example of this procedural analysis is the line called Piemonte-Savoia between Italy (Piossasco) and France (Grand'Ile). It consists of a HVDC-VSC (Voltage Source Converter) [38] cable line, $190 \mathrm{~km}$ long, which will be integrated for $94.3 \mathrm{~km}$ within the infrastructures of the existing highway. The project will be concluded in 2018 [39].

\section{References}

[1] Henningsen, C.G., Müller, K.B., Polster, K., et al.: 'New 400 kV XLPE long distance systems, their first application for the power supply of Berlin'. Proc. of Cigré, Paper 21-109, 1998

[2] Granadino, R., Portillo, M., Planas, J., et al.: 'Undergrounding the First 400 $\mathrm{kV}$ transmission line in Spain using $2500 \mathrm{~mm}^{2}$ XLPE cables in a ventilated tunnel: The Madrid 'Barajas' airport project'. Proc. of Jicable, Paper A1-2, 2003

[3] Sadler, S., Sutton, S., Memmer, H., et al.: '1600 MW electrical power transmission with an EHV XLPE cable system in the underground of London'. Proc. of Cigré, Paper B1-108, 2004

[4] Benato, R. Colla, L., Dambone Sessa, S et al: 'Review of high current rating insulated cable solutions', Electr. Power Syst. Res., 2016, 133, pp. 3641

[5] Benato, R., Paolucci, A.: 'Operating capability of ac EHV mixed lines with overhead and cables links', Electr. Power Syst. Res., 2008, 78, (4), pp. 584594

[6] Benato, R., Gatta, F.M., Lauria, S., et al.: 'Steady-state and transient EHV ac cable shunt reactive compensation assessment'. 43rd Int. Conf. on Large High Voltage Electric Systems, CIGRE, 2010

[7] Orton, H.: 'History of underground power cables', IEEE Electr. Insul. Mag., 2013, 29, (4), pp. 52-57, doi: 10.1109/MEI.2013.6545260

[8] Benato, R., Bernocchi, M., Camilli, L., et al.: 'Compatibility between electrical energy transmission lines and new railway infrastructures'. Proc. of Cigré, Paper B1-308, 2008

[9] Benato, R., Brunello, P., Carlini, E.M., et al: 'Italy-Austria GIL in the new planned railway galleries Fortezza-Innsbruck under Brenner Pass'. Proc. of Cigré, Paper B1-304, 2006

[10] Benato, R., Di Mario, C., Koch, H.: 'High capability applications of long gas insulated lines in structures', IEEE Trans. Power Deliv., 2007, 22, (1), pp. 619-626

[11] Koch, H. (Convenor), Benato, R., Laußegger, L., et al.: 'Application of long high capacity gas-insulated lines in structures'. Cigré Technical Brochure no. 351,2008
[12] Awad, R. (Convenor), Barber, K., Peacock, C., et al.: 'Cable systems in multipurpose or shared structures'. Cigré Technical Brochure no. 403, 2010

[13] Pollaczek, F.: 'Über das Feld einer unendlich langen wechsel stromdurchflossenen Einfachleitung', Electrishe Nachrichten Technik, 1926 , 3, (9), pp. 339-360

[14] Carson, J.R.: 'Wave propagation in overhead wires with ground return', Bell Syst. Tech. J., 1926, 5, pp. 539-554

[15] Papadopoulos, T.A., Tsiamitros, D.A., Papagiannis, G.K. 'Earth return admittances and impedances of underground cables in non-homogeneous earth', IET. Gener. Transm. Distrib., 2011, 5, (2), pp. 161-171

[16] Dommel, H.W.: 'Electromagnetic transients program reference manual (EMTP theory book)' (Bonneville Power Administration, Portland, 1986)

[17] Wedepohl, L.M., Wilcox, D.J.: 'Transient analysis of underground power transmission systems'. Proc. of IEE 120, 1973, pp. 253-260

[18] Benato, R.: 'Multiconductor analysis of underground power transmission systems: EHV AC cables', Electr. Power Syst. Res., 2009, 79, (1), pp. 27-38

[19] Benato, R., Paolucci, A.: 'Multiconductor cell analysis of skin effect in Milliken type cables', Electr. Power Syst. Res., 2012, 90, pp. 99-106

[20] Benato, R., Caldon, R.: 'Application of PLC for the control and the protection of future distribution networks'. Proc. of IEEE Int. Symp. on Power Line Communications and Its Applications, 2007

[21] Benato, R., Dambone Sessa, S., Guglielmi, F.: 'Determination of steady-state and faulty regimes of overhead lines by means of multiconductor cell analysis (MCA)', Energies, 2012, 5, (8), pp. 2771-2793

[22] Benato, R., Caldon, R., Paolucci, A.: 'Algoritmo matriciale per l'analisi di linea ferroviaria ad alta velocità e rispettiva rete di alimentazione', L'Energia Elettrica, 1998, 75, (5), pp. 304-311

[23] Salinas, E. (Convenor), Bottauscio, O., Chiampi, M., et al.: 'Mitigation techniques of power-frequency magnetic fields originated from electric power systems'. Cigré Technical Brochure no. 373, 2009

[24] Del Pino Lopez, J.C., Romero, P.C.: 'Influence of different types of magnetic shields on the thermal behavior and ampacity of underground power cables', IEEE Trans. Power Deliv., 2011, 26, (4), pp. 2659-2667

[25] del Pino Lopez, J.C., Romero, P.C.: 'The effectiveness of compensated passive loops for mitigating underground power cable magnetic fields', IEEE Trans. Power Deliv., 2011, 26, (2), pp. 674-683

[26] Orton, H. (Convenor), Maioli, P., Barnes, T., et al.: 'Impact of EMF on current ratings and cable systems'. Cigré Technical Brochure no. 559, 2013

[27] Abootorabi Zarchi, D., Vahidi, B., Haji, M.M.: 'Optimal configuration of underground cables to maximise total ampacity considering current harmonics', IET. Gener. Transm. Distrib., 2014, 8, (6), pp. 1090-1097

[28] Swaffield, D.J., Lewin, P.L., Payne, D., et al.: 'Effects of modelling assumptions on the rating calculation for externally forced cooled highvoltage cables', IET. Gener. Transm. Distrib., 2009, 3, (5), pp. 496-507

[29] Benato, R., Forzan, M., Marelli, M., et al.: 'Harmonic behaviour of HVDC cables', Electr. Power Syst. Res., 89, pp. 215-222

[30] Benato, R., Dambone Sessa, S., Guglielmi, F., et al.: 'Ground return current behaviour in HVAC insulated cables by means of MCA', Energies, 2014, 7 , (12), pp. 8116-813

[31] Schembari, M., Codino, A., Catapano, A et al: 'Fault current increase due to the progressive undergrounding of a HV subtransmission network'. Proc. of 2015 IEEE 15th Int. Conf. on Environment and Electrical Engineering (EEEIC), 2015

[32] Pokryvailo, A.: 'Behavior of HV cable at short circuit', IEEE Trans. Dielectr. Electr. Insul., 2015, 22, (4), pp. 1763-1768

[33] Donazzi, F., Gaspari, R., Cauzillo, B.A., et al.: 'Research on the performance of $400 \mathrm{kV}$ extruded cable system under short circuit conditions'. Proc. of Cigré, Paper 21-205, 1996

[34] Mori, S., Imai, S., Ninomiya, $\mathrm{K}$, et al. 'Effects of internal conductor to enclousure arcs on $\mathrm{SF}_{6}$ gas insulated transmission lines', IEEE Trans. Appar. Syst., 1983, PAS-102, (4), pp. 860-869

[35] IEC 62271-204: 'High-voltage switchgear and controlgear - Part 204: Rigid gas-insulated transmission lines for rated voltage above $52 \mathrm{kV}$ ', 2011

[36] Rosevear, R.D. (Convenor), Choquetteet, M., Fairhurst, M., et al.: 'HV underground and update of service experience of submarine cable systems'. Cigré Technical Brochure no. 379, 2009

[37] Benato, R., Del Brenna, M., Di Mario, C., et al.: 'A new procedure to compare the social costs of EHV-HV overhead lines and underground XLPE cables'. Proc. of 41st Int. Conf. on Large High Voltage Electric Systems, CIGRE, 2006

[38] Beerten, J., D'Arco, S., Are Suul, J.: 'Frequency-dependent cable modelling for small-signal stability analysis of VSC-HVDC systems', IET. Gener Transm. Distrib., 2016, 10, (6), pp. 1370-1381

[39] Marzinotto, M., Albertini, M., Benard, L., et al.: 'Cable system qualification process for the Italy - France HVDC intertie'. Proc. of 41th Int. Conf. on Large High Voltage Electric Systems, CIGRE, Paper: B1-109, 2016 